\title{
Berm and Dune Erosion during a Storm
}

\author{
Nobuhisa Kobayashi ${ }^{1}$; Mitchell Buck ${ }^{2}$; Andres Payo ${ }^{3}$; and Bradley D. Johnson ${ }^{4}$
}

\begin{abstract}
The prediction of berm and dune erosion during a storm is essential for storm damage assessment. Simple and transparent formulas for the cross-shore and longshore transport rates of suspended sediment and bed load on beaches are proposed and incorporated into a combined wave and current model to predict the berm and dune erosion under normally and obliquely incident irregular waves. Two small-scale experiments for two different berm profiles were conducted for the calibration of the developed numerical model. The calibrated numerical model is shown to predict the measured berm and dune erosion in these experiments as well as dune erosion measured in three large-scale tests with errors less than a factor of two. The numerical model is used to examine the effects of the wave period and incident wave angle on the berm and dune erosion. These effects are computed to be within a factor of two.
\end{abstract}

DOI: 10.1061/(ASCE)0733-950X(2009)135:1(1)

CE Database subject headings: Berms; Dunes; Sand; Erosion; Beaches; Sediment transport; Bed loads; Storms; Surf zone.

\section{Introduction}

A beach with a wide berm and a high dune provides storm protection and damage reduction, recreational and economical benefits, and biological habitats for plants and animals. A beach nourishment project in the United States normally includes the construction and maintenance of a wide berm and a high dune (Coastal Engineering Manual 2003). Empirical models based on an equilibrium beach profile have been developed to predict timedependent beach and dune erosion during a storm (Kriebel and Dean 1985; Kobayashi 1987; Larson and Kraus 1989). These models may be able to predict dune erosion within an error of a factor of about two if they are calibrated for each specific site. However, the empirical models predict only erosion under normally incident waves and cannot be used for the performance evaluation of a beach nourishment project under sequences of storms. Numerical models based on sediment transport processes have also been developed (e.g., Nairn and Southgate 1993). However, the process-based models may not necessarily be more accurate at present.

This study presents our continuing effort to improve the predictive capability of sediment transport on beaches by synthesizing available data and formulas for suspended sand and bed load transport rates (Kobayashi et al. 2008b). The aim is to develop a simple and robust model that is suited for engineering applications. In this study, small-scale experiments were conducted in a

${ }^{1}$ Professor \& Director, Center for Applied Coastal Research, Univ. of Delaware, Newark, DE 19716 (corresponding author). E-mail: nk@ coastal.udel.edu

${ }^{2}$ Coastal Engineer, Woods Hole Group, 81 Technology Park Dr., E. Falmouth, MA 02536.

${ }^{3}$ Coastal Scientist, SIDMAR, Avda. Pais de Valencia, No. 22, Benissa, Alicante E-03720, Spain.

${ }^{4}$ Research Engineer, U.S. Army Engineer Research and Development Center, 3909 Halls Ferry Rd., Vicksburg, MS 39180-6199.

Note. Discussion open until June 1, 2009. Separate discussions must be submitted for individual papers. The manuscript for this paper was submitted for review and possible publication on September 21, 2007; approved on May 2, 2008. This paper is part of the Journal of Waterway, Port, Coastal, and Ocean Engineering, Vol. 135, No. 1, January 1, 2009. CASCE, ISSN 0733-950X/2009/1-1-10/\$25.00. wave flume to examine the effect of berm geometry on the resulting berm and dune erosion. No accepted similitude may exist for sediment transport on beaches but a sediment transport model should be able to predict berm and dune erosion in small-scale and large-scale experiments if it includes basic sediment dynamics sufficiently. Simple formulas are proposed for the transport rates of suspended sand and bed load on beaches. These formulas are combined with the computationally efficient hydrodynamic model by Kobayashi et al. (2007) to predict the profile change of a beach with a berm and a dune during a storm. The combined model is verified using our small-scale experiments as well as the large-scale dune erosion tests conducted by van Gent et al. (2006) to examine the influence of wave periods. The verified model is then used to predict berm and dune erosion under obliquely incident waves.

In the following, the small-scale experiments are described first. The sediment transport models are presented and compared with the small-scale experiments. Comparison with the largescale dune erosion tests is shown and the influence of wave periods is examined. Computation is made to examine the effect of the incident wave angle on berm and dune erosion. Finally, the findings of this study are summarized.

\section{Small-Scale Experiments}

Experiments were conducted in a wave flume that was $30 \mathrm{~m}$ long, $1.15 \mathrm{~m}$ wide, and $1.5 \mathrm{~m}$ high as shown in Fig. 1. The sand in the flume was well sorted and its median diameter was $0.18 \mathrm{~mm}$. The measured fall velocity, specific gravity, and porosity of the sand were $2.0 \mathrm{~cm} / \mathrm{s}, 2.6$, and 0.4 , respectively. The water depth in the flume was $0.9 \mathrm{~m}$ in the absence of storm surge where the still water level (SWL) in the flume was increased to simulate storm surge. A piston-type wave paddle was used to generate irregular waves, based on the TMA spectrum. The spectral peak period $T_{p}$ was $2.57 \mathrm{~s}$. The spectral significant wave height $H_{m 0}$ increased somewhat with the increase of SWL in the flume and was in the range of $17.8-19.2 \mathrm{~cm}$. The irregular waves were generated in a burst of $400 \mathrm{~s}$ to avoid seiche in the flume. The initial transition of $20 \mathrm{~s}$ was removed for the subsequent analysis of data sampled at a rate of $20 \mathrm{~Hz}$. The initial profile shown in Fig. 1 was the 


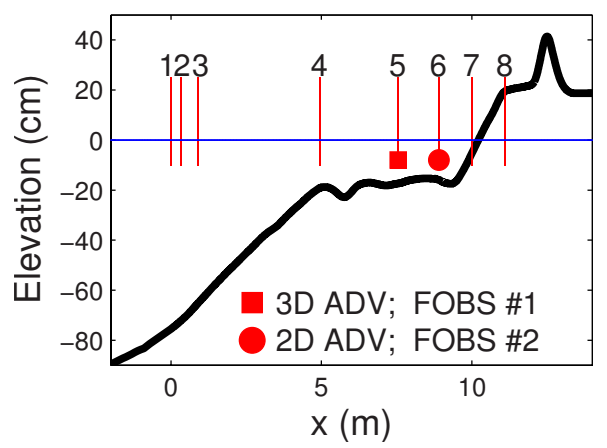

Fig. 1. Setup for berm and dune erosion experiment

quasi-equilibrium profile for $T_{p}=2.57 \mathrm{~s}$ in the previous experiment by Schmied et al. (2006) except that a berm with a dune was constructed near and above the shoreline.

Eight wave gauges were used to measure the time series of the free surface elevation $\eta$ above SWL. Wave Gauges 1-3 were located outside the surf zone and used to estimate the average reflection coefficient (Kobayashi et al. 2005). Wave Gauges 4-6 measured irregular breaking waves in the surf zone. Wave Gauges 7 and 8 were partially buried in the sand to measure broken waves in very shallow water. The eight wave gauges were calibrated by raising and lowering SWL in the wave flume. This calibration procedure ensured that the sand above SWL was wet during the experiment. Two acoustic-Doppler velocimeters (ADVs) with a three-dimensional (3D) down-looking probe and a 2D sidelooking probe were used to measure the velocities at an elevation of $2 \mathrm{~cm}$ above the local bottom at the locations of wave Gauges 5 and 6. A fiber optic sediment monitor (FOBS) with two sensors was used to measure the sand concentrations at the locations of the velocity measurements. The FOBS sensors were placed at the flume centerline. The ADVs and wave Gauges 5 and 6 were placed at the alongshore locations $14.5 \mathrm{~cm}$ from the flume centerline.

Two experiments were conducted for two different berm profiles as shown in Fig. 2. The horizontal coordinate $x$ is taken to be positive onshore with $x=0$ at wave Gauge 1 . The vertical coordinate $z$ is positive upward with $z=0$ at the still water level of the initial profile. The berm in Experiment $\mathrm{H}$ was high and narrow, whereas the berm in Experiment $\mathrm{L}$ was low and wide. The sand volume between $x=9.07 \mathrm{~m}$ and the dune crest was approximately the same in Experiments $\mathrm{H}$ and $\mathrm{L}$.

For each experiment, a series of Tests A-F were conducted by changing the still water level $S$ above $z=0$ as summarized in

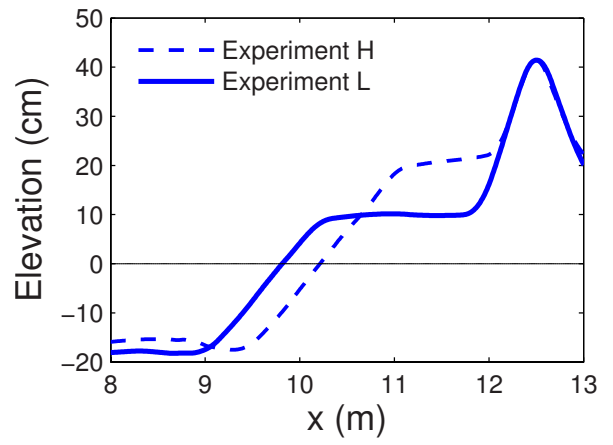

Fig. 2. High and narrow berm Experiment $\mathrm{H}$ and low and wide berm Experiment L
Table 1. Wave Conditions at Wave Gauge 1 for Tests A-F with Different Still Water Levels $S$ in Experiments $\mathrm{H}$ and $\mathrm{L}$

\begin{tabular}{|c|c|c|c|c|c|c|c|c|c|}
\hline \multirow[b]{3}{*}{ Test } & \multirow{3}{*}{$\begin{array}{c}S \\
(\mathrm{~cm})\end{array}$} & \multirow[b]{3}{*}{$N_{b}$} & \multirow{3}{*}{$\begin{array}{l}T_{e} \\
\text { (h) }\end{array}$} & \multicolumn{3}{|c|}{ Experiment $\mathrm{H}$} & \multicolumn{3}{|c|}{ Experiment L } \\
\hline & & & & \multirow{2}{*}{$\begin{array}{l}H_{m o} \\
(\mathrm{~cm})\end{array}$} & \multicolumn{2}{|c|}{$R$} & \multirow{2}{*}{$\begin{array}{l}H_{m o} \\
(\mathrm{~cm})\end{array}$} & \multicolumn{2}{|c|}{$R$} \\
\hline & & & & & Meas. & Comp. & & Meas. & Comp \\
\hline A & 0 & 9 & 1.00 & 18.8 & 0.22 & 0.18 & 18.4 & 0.14 & 0.18 \\
\hline B & 5 & 9 & 2.00 & 18.8 & 0.16 & 0.18 & 18.9 & 0.13 & 0.16 \\
\hline $\mathrm{C}$ & 10 & 9 & 3.00 & 18.2 & 0.18 & 0.18 & 18.7 & 0.18 & 0.17 \\
\hline D & 15 & 6 & 3.67 & 19.2 & 0.21 & 0.18 & 18.6 & 0.22 & 0.18 \\
\hline E & 5 & 11 & 4.89 & 18.7 & 0.13 & 0.15 & 18.4 & 0.13 & 0.15 \\
\hline $\mathrm{F}$ & 0 & 11 & 6.11 & 17.8 & 0.13 & 0.14 & 18.5 & 0.13 & 0.13 \\
\hline
\end{tabular}

Table 1 where $N_{b}=$ number of $400 \mathrm{~s}$ bursts for each test; $T_{e}$ $=$ end time of each test starting from time $=0$ at the beginning of Test A. The water level $S$ associated with storm surge and tide was increased by an increment of $5 \mathrm{~cm}$. The berm was eroded during Tests A and B. For the given water level, the wave action lasted for $1 \mathrm{~h}$ until Test D which was stopped when the dune was breached. The dune breaching in Test $\mathrm{D}$ occurred after six bursts in both experiments. The water level $S$ was decreased in Tests E and $\mathrm{F}$ and $N_{b}$ was increased to 11 because the beach profile change was slowed. Beach profiles were measured along three cross-shore transects. The measured profiles were essentially uniform alongshore except for the breached dune whose geometry was presented in the report by Buck et al. (2007). The average profile is used for the subsequent comparison with the present numerical model which is one dimensional in the $x$ direction and cannot predict dune breaching. The dune breaching in these experiments was caused by one large wave overwash event at the alongshore location where the dune crest was lowered earlier by scarping and minor overwash. The breaching of a dune and a barrier island is an important unsolved problem as reviewed by Donnelly et al. (2006) but is not analyzed in this study.

The free surface elevations, velocities, and sand concentrations were measured for each burst. The mean and standard deviation of the measured time series are tabulated by Buck et al. (2007). The mean and standard deviation during each test did not change much except for the mean $\bar{\eta}$ and the standard deviation $\sigma_{\eta}$ of the free surface elevation $\eta$ at wave Gauges 7 and 8 for the tests with large profile changes at these gauge locations. Table 1 lists the significant wave height $H_{m 0}$ defined as $H_{m 0}=4 \sigma_{\eta}$ and the reflection coefficient $R$ at wave Gauge 1 for each test where the listed value is the average of the measured values for $N_{b}$ bursts. The spectral peak period at wave Gauge 1 was $T_{p}=2.57 \mathrm{~s}$ for all the bursts. The measured values of $R$ were larger when the beach slopes near SWL were larger for Tests HA, HD, and LD where the letter $\mathrm{H}$ or $\mathrm{L}$ is prefixed to distinguish the two experiments. The measured profiles are presented in the subsequent comparison with the computed profiles by the numerical model. The computed values of $R$ listed in Table 1 are explained later.

The comparison of Experiments $\mathrm{H}$ and $\mathrm{L}$ is presented concisely in Fig. 3 which shows the eroded area landward of the intersection point located at $x=9.07 \mathrm{~m}$ in Fig. 2. The low and wide berm eroded faster during Tests $\mathrm{A}$ and $\mathrm{B}$ with the still water level $S=0$ and $5 \mathrm{~cm}$ above the datum $z=0$ but recovered slightly during test C with $S=10 \mathrm{~cm}$ when the still water level was at the berm elevation. The high and narrow berm eroded fastest during Test D with $S=15 \mathrm{~cm}$. The still water level was lowered to $S$ $=5 \mathrm{~cm}$ and $S=0 \mathrm{~m}$ during Tests $\mathrm{E}$ and $\mathrm{F}$, respectively. A slight recovery occurred above SWL but erosion below SWL was larger 


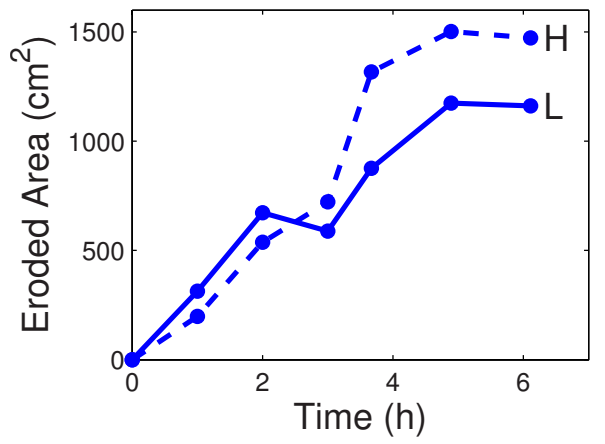

Fig. 3. Temporal variation of eroded area for Experiments $\mathrm{H}$ and $\mathrm{L}$

during test $\mathrm{E}$. The detailed temporal variation of the eroded area was different for the two different berms but the eroded area difference was less than about $40 \%$ and smaller than the difference in the berm height and width. This experimental finding is consistent with the present practice described in the Coastal Engineering Manual (2003). The total berm and dune area per unit alongshore length is of primary importance. The desirable berm height and width also depend on other factors. The high berm in Experiment H was scarped after Test HA. A scarped berm causes inconvenience to beach users.

\section{Sediment Transport Model}

A time-dependent sediment transport model such as that by Kobayashi and Johnson (2001) is physically appealing because it predicts intense but intermittent sand suspension due to breaking waves. The berm and dune erosion observed in the present experiments were slow, however, indicating that a time-averaged model is appropriate in predicting the profile evolution due to small net cross-shore sediment transport. However, the small net transport rate is difficult to predict accurately.

The time-averaged model by Kobayashi et al. (2007) for longshore current and suspended sand transport on a beach of alongshore uniformity is extended here to predict the cross-shore and longshore transport rates of suspended sediment and bed load. The combined wave and current model by Kobayashi et al. (2007) is summarized as follows. The time-averaged continuity, crossshore momentum, longshore momentum, and wave energy equations are used to predict the cross-shore variations of the mean free surface elevation $\bar{\eta}$ above SWL, the free surface standard deviation $\sigma_{\eta}$, the depth-averaged cross-shore current $\bar{U}$, and the depth-averaged longshore current $\bar{V}$. The overbar indicates time averaging. The period of irregular waves is represented by the spectral peak period $T_{p}$ at $x=0$ outside the surf zone. The incident waves are assumed to be unidirectional and the wave angle $\theta$ relative to the shore normal is computed using Snell's law. The energy equation for a roller is used to estimate the roller volume flux. The wave reflection coefficient $R$ is estimated from the cross-shore wave energy flux at the still water shoreline (Kobayashi et al. 2005).

The time-averaged cross-shore and longshore bottom shear stresses in the momentum equations and the time-averaged energy dissipation rate $D_{f}$ due to bottom friction are expressed in terms of the depth-averaged cross-shore and longshore velocities $U$ and $V$ which are assumed to be expressed as

$$
U=\bar{U}+r \sigma_{T} \cos \theta ; \quad V=\bar{V}+r \sigma_{T} \sin \theta
$$

where $r=$ Gaussian variable whose mean and standard deviation are zero and unity, respectively; and $\sigma_{T}=$ standard deviation of the depth-averaged velocity of the irregular waves propagating in the direction of $\theta$. Linear progressive wave theory is used to obtain

$$
\sigma_{T}=C_{p} \sigma_{\eta} / \bar{h} ; \quad \bar{h}=\bar{\eta}+S-z_{b}
$$

where $C_{p}=$ linear wave phase velocity in the mean water depth $\bar{h}$ corresponding to the spectral peak period $T_{p}$; and $S$ and $z_{b}=$ still water level and bottom elevation relative to the datum $z=0$. It is noted that the assumption of shallow water employed by Kobayashi et al. (2007) is not made in Eq. (2) and the expression for the onshore volume flux due to linear progressive waves in the continuity equation (Kobayashi et al. 2008a). The equations of the time-averaged bottom stresses and the dissipation rate $D_{f}$ given by Kobayashi et al. (2007) are based on Eq. (1) along with the assumption of the equivalency of the time and probabilistic averaging. These equations include the dimensionless functions which need to be integrated numerically. Kobayashi et al. (2008a) integrated these functions analytically with errors less than $35 \%$. These analytical expressions are used here for computational efficiency and numerical stability.

The combined wave and current model predicts the crossshore variations of the hydrodynamic variables used in the following sediment transport model for given beach profile, water level, and seaward wave conditions at $x=0$. The bottom sediment is assumed to be uniform and characterized by $d_{50}=$ median diameter; $w_{f}=$ sediment fall velocity; $s=$ sediment specific gravity; and $n_{p}=$ porosity of bottom sediment.

First, the cross-shore variation of the degree of sediment movement is estimated using the critical Shields parameter $\psi_{c}$ (Madsen and Grant 1977) which is taken as $\psi_{c}=0.05$. The instantaneous bottom shear stress $\tau_{b}^{\prime}$ is assumed to be given by $\tau_{b}^{\prime}=0.5 \rho f_{b}\left(U^{2}+V^{2}\right)$ where $\rho=$ water density; and $f_{b}=$ bottom friction factor taken as $f_{b}=0.015$ as explained by Kobayashi et al. (2005). The sediment movement is assumed to occur when $\left|\tau_{b}^{\prime}\right|$ exceeds the critical shear stress, $\rho g(s-1) d_{50} \psi_{c}$ where $g=$ gravitational acceleration. The probability $P_{b}$ of sediment movement can be shown to be the same as the probability of $\left(r-r_{m}\right)^{2}>F_{b}^{2}=\left(R_{b}^{2}-F_{m}^{2}\right)$ where $R_{b}=\left[2 g(s-1) d_{50} \psi_{c} f_{b}^{-1}\right]^{0.5} / \sigma_{T}$ and $r_{m}$ and $F_{m}$ are defined by

$$
r_{m}=-\left(U_{*} \cos \theta+V_{*} \sin \theta\right) ; \quad F_{m}=V_{*} \cos \theta-U_{*} \sin \theta
$$

where $U_{*}=\bar{U} / \sigma_{T}$ and $V_{*}=\bar{V} / \sigma_{T}$. For the Gaussian variable $r, P_{b}$ is given by

$$
P_{b}=\frac{1}{2} \operatorname{erfc}\left(\frac{F_{b}-r_{m}}{\sqrt{2}}\right)+\frac{1}{2} \operatorname{erfc}\left(\frac{F_{b}+r_{m}}{\sqrt{2}}\right) \text { for } F_{b}^{2}>0
$$

and $P_{b}=1$ for $F_{b}^{2} \leqslant 0$ where erfc=complementary error function.

Second, the cross-shore variation of the degree of sediment suspension is estimated using the experimental finding of Kobayashi et al. (2005) who showed that the turbulent velocities measured in the vicinity of the bottom were related to the energy dissipation rate due to bottom friction. Representing the magnitude of the instantaneous turbulent velocity by $\left(D_{f}^{\prime} / \rho\right)^{1 / 3}$ with $D_{f}^{\prime}=0.5 \rho f_{b}\left(U^{2}+V^{2}\right)^{1.5}$, the probability $P_{s}$ of sediment suspension is assumed to be the same as the probability of $\left(D_{f}^{\prime} / \rho\right)^{1 / 3}$ exceeding the sediment fall velocity $w_{f}$. The probability $P_{s}$ is then equal to the probability of $\left(r-r_{m}\right)^{2}>F_{s}^{2}=\left(R_{s}^{2}-F_{m}^{2}\right)$ with $R_{s}=\left[\left(2 / f_{b}\right)^{1 / 3} w_{f} / \sigma_{T}\right]$ and is given by 


$$
P_{s}=\frac{1}{2} \operatorname{erfc}\left(\frac{F_{s}-r_{m}}{\sqrt{2}}\right)+\frac{1}{2} \operatorname{erfc}\left(\frac{F_{s}+r_{m}}{\sqrt{2}}\right) \text { for } F_{s}^{2}>0
$$

and $P_{s}=1$ for $F_{s}^{2} \leqslant 0$. If $P_{s}>P_{b}$, use is made of $P_{s}=P_{b}$ assuming that sediment suspension occurs only when sediment movement occurs.

Third, the suspended sediment volume $V_{s}$ per unit horizontal bottom area is estimated by modifying the sediment suspension model by Kobayashi and Johnson (2001)

$$
V_{s}=P_{s} \frac{e_{B} D_{r}+e_{f} D_{f}}{\rho g(s-1) w_{f}}\left(1+S_{b}^{2}\right)^{0.5} ; \quad S_{b}=\frac{\partial z_{b}}{\partial x}
$$

where $S_{b}=$ cross-shore bottom slope; and $e_{B}$ and $e_{f}=$ suspension efficiencies for the energy dissipation rates $D_{r}$ and $D_{f}$ due to wave breaking and bottom friction, respectively. The rates $D_{r}$ and $D_{f}$ involved in the roller and wave energy equations are computed by the combined wave and current model. Use is made of their calibrated values of $e_{B}=0.005$ and $e_{f}=0.01$. The sediment suspension probability $P_{s}$ is added in Eq. (6) to ensure $V_{s}=0$ if $P_{s}=0$. The term $\left(1+S_{b}^{2}\right)^{0.5}=$ actual bottom area per unit horizontal area and essentially unity except for very steep slopes. The cross-shore and longshore suspended sediment transport rates $q_{s x}$ and $q_{s y}$ are expressed as

$$
q_{s x}=a \bar{U} V_{s} ; \quad q_{s y}=\bar{V} V_{s}
$$

where $a=$ empirical suspended load parameter. The parameter $a$ accounts for the onshore suspended sediment transport due to the positive correlation between the time-varying cross-shore velocity and suspended sediment concentration. The value of $a$ increases to unity as the positive correlation decreases to zero. For the three small-scale equilibrium profile experiments conducted by Kobayashi et al. (2005), $a$ was in the range of 0.1-0.4 The cross-shore suspended sediment transport rate $q_{s x}$ is negative (offshore) because the return (undertow) current $\bar{U}$ is negative (offshore). On the other hand, the longshore suspended sediment transport rate $q_{s y}$ in Eq. (7) neglects the correlation between the time-varying longshore velocity and suspended sediment concentration, which appears to be very small if the longshore current $\bar{V}$ is sufficiently large.

Fourth, the formulas for the cross-shore and longshore bed load transport rates $q_{b x}$ and $q_{b y}$ are devised somewhat intuitively because bed load in the surf zone has never been measured. The time-averaged rates $q_{b x}$ and $q_{b y}$ are tentatively expressed as

$$
q_{b x}=B \overline{\left(U^{2}+V^{2}\right) U} ; \quad q_{b y}=B \overline{\left(U^{2}+V^{2}\right) V}
$$

where $B=$ empirical parameter. Eq. (8) may be regarded as a quasi-steady application of the formula of Meyer-Peter and Mueller (for example, Ribberink 1998). Substitution of $U$ and $V$ given in Eq. (1) yields the equations for $q_{b x}$ and $q_{b y}$ for an arbitrary wave angle $\theta$. These equations are adjusted so that $q_{b x}$ reduces to the onshore bed load formula proposed by Kobayashi et al. (2008b) for $\theta=0$. The proposed bed load formulas are written as

$$
\begin{gathered}
q_{b x}=\frac{b P_{b}}{g(s-1)} \sigma_{T}^{3}\left(1+U_{*} V_{*}^{2}+2 F_{m} \sin \theta\right) G_{s} \\
q_{b y}=\frac{b P_{b}}{g(s-1)} \sigma_{T}^{3}\left[V_{*}\left(1+U_{*}^{2}+V_{*}^{2}\right)-2 r_{m} \sin \theta\right]
\end{gathered}
$$

where $b=$ empirical bed load parameter; and $G_{s}=$ bottom slope function. The sediment movement probability $P_{b}$ given in Eq. (4) accounts for the initiation of sediment movement. For normally incident waves with $\theta=0$ and $\bar{V}=0$, Eqs. (9) and (10), yield $q_{b x}=b P_{b} \sigma_{T}^{3} G_{s} /[g(s-1)]$ and $q_{b y}=0$. Kobayashi et al. (2008b) calibrated $b=0.002$ using the 20 water tunnel tests of Ribberink and Al Salem (1994) and the four large-scale wave flume tests of Dohmen-Janssen and Hanes (2002). However, these tests were conducted for nonbreaking waves and the assumed value of $b=0.002$ is uncertain in surf and swash zones.

The bottom slope function $G_{s}$ was introduced by Kobayashi et al. (2008b) to account for the effect of the steep cross-shore slope $S_{b}$ on the bed load transport rate and is expressed as

$$
\begin{gathered}
G_{s}=\tan \phi /\left(\tan \phi+S_{b}\right) \quad \text { for }-\tan \phi<S_{b}<0 \\
G_{s}=\left(\tan \phi-2 S_{b}\right) /\left(\tan \phi-S_{b}\right) \quad \text { for } 0<S_{b}<\tan \phi
\end{gathered}
$$

where $\phi=$ angle of internal friction of the sediment and $\tan \phi$ $\simeq 0.63$ for sand (Bailard 1981). For $S_{b}=0, G_{s}=1$. Eq. (11) corresponds to the functional form of $G_{s}$ used by Bagnold (1966) for steady stream flow on a downward slope with $S_{b}<0$ where the downward slope increases $q_{b x}$. Eq. (12) ensures that $G_{s}$ approaches negative infinity as the upward slope $S_{b}$ approaches $\tan \phi$ and that Eqs. (11) and (12) reduce to $G_{s} \simeq\left(1-S_{b} / \tan \phi\right)$ for $\left|S_{b}\right| \ll \tan \phi$. Eq. (9) with $G_{s}$ given by Eqs. (11) and (12) implies that the bed load transport rate $q_{b x}$ is positive (onshore) for $S_{b}<(\tan \phi) / 2$ and negative (offshore) for $S_{b}>(\tan \phi) / 2$. Use is made of $\left|G_{s}\right|<G_{m}=10$ to avoid an infinite value in the computation. The computed profile change is not very sensitive to the assumed value of $G_{m}$ because the beach profile changes in such a way to reduce a very steep slope except in the region of scarping.

The landward marching computation of the present timeaveraged model ends at the cross-shore location $x=x_{m}$ where the mean water depth $\bar{h}$ is less than about $1 \mathrm{~cm}$. The following simple procedure for scarping is adopted to deal with the zone with the bottom slope $S_{b}>\tan \phi$. The cross-shore total sediment transport rate $q_{x}=\left(q_{s x}+q_{b x}\right)$ at $x=x_{m}$ is denoted by $q_{x m}$. If $q_{x m}$ is negative (offshore), $q_{x}$ is extrapolated linearly to estimate $q_{x}$ on the scarped face with $S_{b}>\tan \phi$

$$
q_{x}=q_{x m}\left(x_{e}-x\right) /\left(x_{e}-x_{m}\right) \text { for } x_{m}<x<x_{e}
$$

where $x_{e}=$ landward limit of the scarped face whose slope is larger than $\tan \phi$. The extrapolated $q_{x}$ is in the range of $q_{x m} \leqslant q_{x} \leqslant 0$ and the scarping zone is eroded due to the offshore sediment transport. This simple procedure does not allow onshore sediment transport due to wave overwash (Kobayashi et al. 1996).

Finally, the cross-shore beach profile change is computed using the continuity equation of bottom sediment for the case of alongshore uniformity

$$
\left(1-n_{p}\right) \frac{\partial z_{b}}{\partial t}+\frac{\partial q_{x}}{\partial x}=0
$$

where $t=$ slow morphological time for the change of the bottom elevation $z_{b}$. Eq. (14) is solved using an explicit Lax-Wendroff numerical scheme (for example, Nairn and Southgate 1993) to obtain the bottom elevation at the next time level. This computation procedure is repeated starting from the initial bottom profile until the end of a profile evolution test. The computation time is of the order of $10^{-3}$ of the test duration.

\section{Comparison with Small-Scale Experiments}

The beach profile evolution model developed for the arbitrary incident wave angle $\theta$ is compared with Experiments $\mathrm{H}$ and $\mathrm{L}$ for 


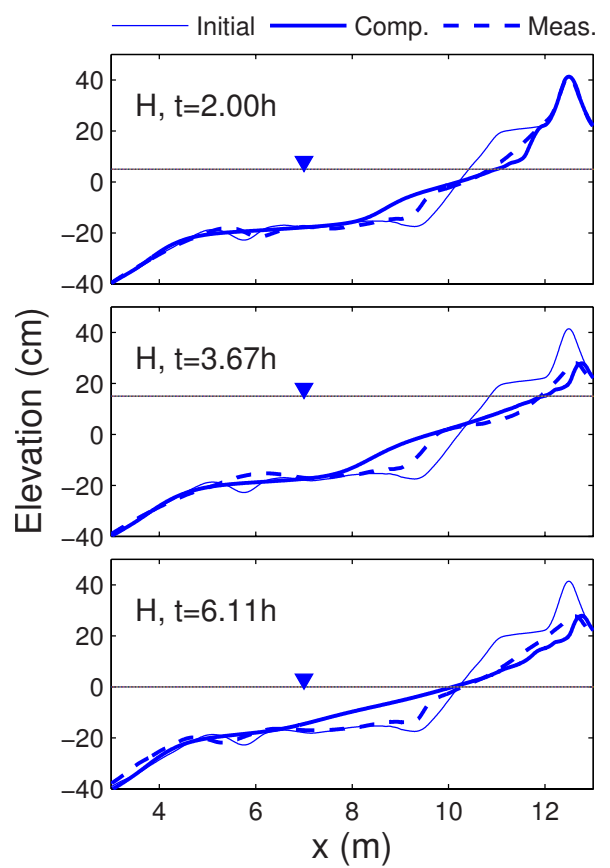

Fig. 4. Measured and computed beach profiles at time $t=2.00,3.67$, and $6.11 \mathrm{~h}$ for Experiment $\mathrm{H}$

the normally incident waves with $\theta=0$. The measured initial profile at time $t=0$ is specified as input. The fine sand is characterized by $d_{50}=0.18 \mathrm{~mm}, w_{f}=2.0 \mathrm{~cm} / \mathrm{s}, s=2.6$, and $n_{p}=0.4$. The time series of the measured values of $S, T_{p}, H_{m o}=4 \sigma_{\eta}$, and $\bar{\eta}$ at $x=0$ are specified as the seaward boundary conditions where the wave setdown $\bar{\eta}$ at $x=0$ was approximately $-0.1 \mathrm{~cm}$ and is not listed in Table 1. The landward marching computation of the wave and current model by Kobayashi et al. (2007) is made using the constant nodal spacing of $\Delta x=1 \mathrm{~cm}$. The empirical parameters of the present model are specified above in relation to the sediment transport model. The breaker ratio parameter $\gamma$ involved in the energy dissipation rate due to wave breaking was calibrated as $\gamma=0.8$ for the equilibrium beach profile experiment by Kobayashi et al. (2005) which corresponded to Experiments H and L without the berm and dune. This calibrated value is found to yield a good agreement with the measured cross-shore variation of $\sigma_{\eta}$ as shown in the following paragraphs.

The only parameter calibrated here is the suspended load parameter $a$ in Eq. (7). The simultaneous measurements of the fluid velocity and suspended sand concentration were made above the gentle slope as shown in Fig. 1. The correlation coefficients between the horizontal velocity and sand concentration were on the order of 0.1 and similar to those in the equilibrium profile experiments by Kobayashi et al. (2005) which yielded a typical value of $a=0.2$. However, $a=0.2$ does not yield sufficient offshore suspended sediment transport, resulting in the underprediction of the berm and dune erosion. The berm and dune with the eroding steep slopes may have reduced the correlation between the horizontal velocity and large sand concentration but the velocity and concentration could not be measured in very shallow water. The reduced correlation increases the value of $a$ as explained in relation to Eq. (7). The value of $a$ is empirically adjusted as

$$
a=0.2+\left(S_{b} / \tan \phi\right)^{0.5} \text { for } S_{b}>0
$$

where $S_{b}=$ local bottom slope and $\tan \phi=$ limiting sand slope of 0.63 as explained in Eqs. (11) and (12). Eq. (15) is applicable

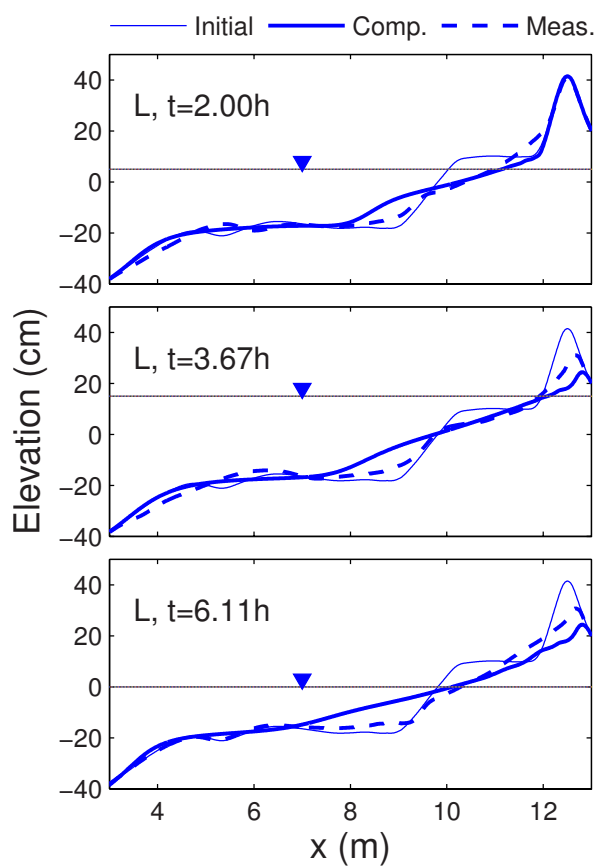

Fig. 5. Measured and computed beach profiles at time $t=2.00,3.67$, and $6.11 \mathrm{~h}$ for Experiment $\mathrm{L}$

only for the upward slope in the onshore direction and $a=0.2$ for $S_{b} \leqslant 0$.

The entire comparison of the numerical model with experiments $\mathrm{H}$ and L presented in the report by Buck et al. (2007) is summarized as follows. Fig. 4 compares the measured and computed beach profiles at time $t=2.00,3.67$, and $6.11 \mathrm{~h}$ corresponding to the end of Tests $\mathrm{B}, \mathrm{D}$, and $\mathrm{F}$, respectively, for Experiment H. The still water level of each test is indicated in each panel. The numerical model predicts the berm and dune erosion well but does not reproduce the measured profile undulations including the relatively steep slope below the datum $z=0$. The numerical model does not include wave overwash and cannot predict the accretion landward of the dune crest due to minor overwash events that occurred during Test HD with the highest still water level $S=15 \mathrm{~cm}$. Fig. 5 shows a comparison for Experiment L. The overall agreement is similar but the dune erosion is overpredicted due to the adopted empirical adjustment of $a$ given by Eq. (15). A few different adjustments were tried but none reproduced the dune erosion accurately for both experiments.

Fig. 6 compares the measured and computed temporal variations of the eroded area for Experiments $\mathrm{H}$ and $\mathrm{L}$ where the eroded area is defined as the decrease of the area landward of $x=9.07 \mathrm{~m}$ in the same way as in Fig. 3. The numerical model with the calibrated $a$ predicts the eroded area within a factor of two but is not accurate enough to predict the detailed temporal variations because the detailed profile changes are not predicted accurately in Figs. 4 and 5.

Fig. 7 compares the computed and measured cross-shore variations of $(S+\bar{\eta}), \sigma_{\eta}, \bar{U}$, and $\sigma_{U}$ for Test LD where the computed and measured bottom elevations at $t=3.67 \mathrm{~h}$ at the end of Test LD are shown in Fig. 5. The measured values from the six bursts during Test LD were almost the same and are plotted together in Fig. 7, whereas the computed values in Fig. 7 correspond to those at $t=3.67 \mathrm{~h}$. The mean water level $(S+\bar{\eta})$ above $z=0$ is predicted to increase appreciably above the eroded berm landward of wave Gauge 8 located at $x=11.1 \mathrm{~m}$ in Fig. 1 . The standard deviation $\sigma_{\eta}$ 


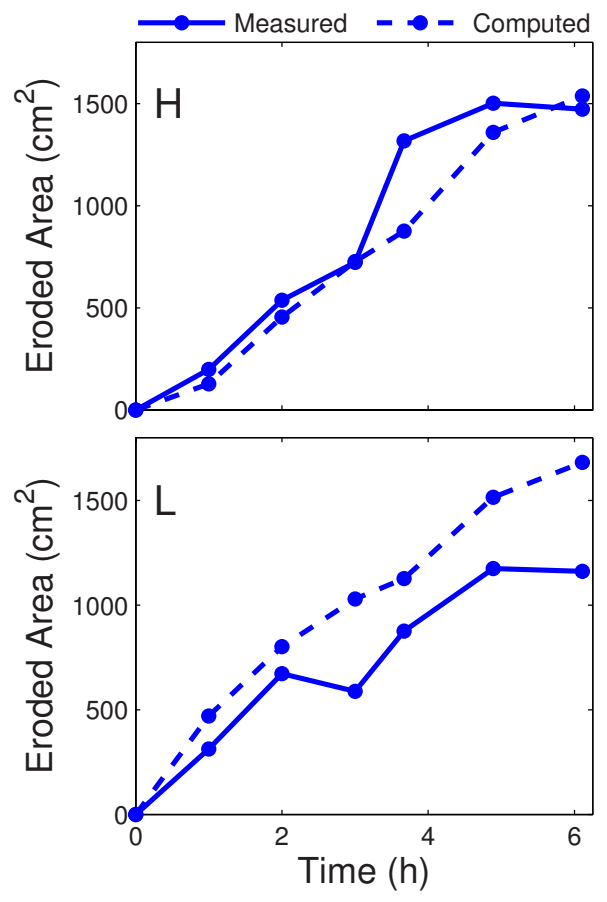

Fig. 6. Measured and computed eroded areas for Experiments $\mathrm{H}$ (top) and L (bottom)

representing the wave height increases somewhat due to wave shoaling and decreases due to wave breaking. The disagreement between the computed and measured values of $\sigma_{\eta}$ in shallow water landward of $x=8 \mathrm{~m}$ is partly related to the disagreement of the computed and measured bottom profiles shown in Fig. 5. The comparisons of $\bar{U}$ and $\sigma_{U}$ are not rigorous because the horizontal velocity measured $2 \mathrm{~cm}$ above the local bottom is expected to be less than the depth-averaged velocity used in the numerical model. The offshore (negative) return current $\bar{U}$ is predicted to be as large as the standard deviation $\sigma_{U}$ above the eroded berm but the velocity could not be measured in very shallow water.

The comparison of $(S+\bar{\eta}), \sigma_{\eta}, \bar{U}$, and $\sigma_{U}$ for the other tests are presented in the report by Buck et al. (2007) and the agreement is similar to that shown in Fig. 7. The numerical model predicts the wave reflection coefficient $R$ within an error of $30 \%$ as shown in Table 1 . The mean and standard deviation of the sand concentration measured $2 \mathrm{~cm}$ above the local bottom were similar to those in the equilibrium profile experiments by Kobayashi et al. (2005) who measured the concentrations of the same sand at several elevations. The suspended sand volume $V_{s}$ used in Eq. (7) could not be estimated from the mean concentration measured at the single elevation. On the other hand, the cross-shore variations of the variables predicted by the present sediment transport model are presented later when the effect of the incident wave angle on the berm and dune erosion is examined.

\section{Comparison with Large-Scale Dune Erosion Tests}

The dune erosion tests by van Gent et al. (2006) were conducted in the Delta flume which is $225 \mathrm{~m}$ long, $5 \mathrm{~m}$ wide, and $7 \mathrm{~m}$ high. The fine sand for these tests was characterized by $d_{50}=0.20 \mathrm{~mm}$, $w_{f}=2.5 \mathrm{~cm} / \mathrm{s}, s=2.65$, and $n_{p}=0.4$. The seaward slope and height of the dune constructed in the flume was $2 / 3$ and $1.67 \mathrm{~m}$ above the datum $z=0$ where the still water level was kept constant
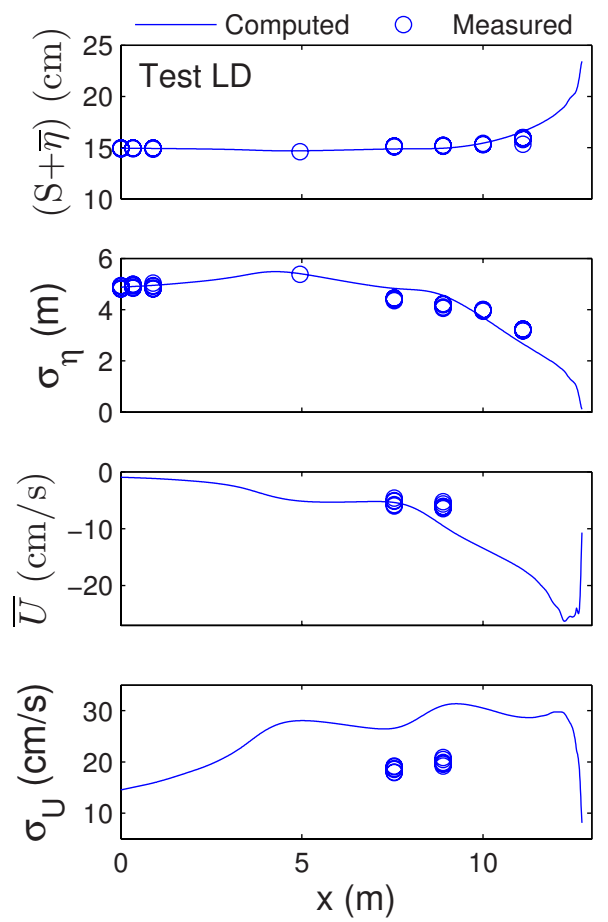

Fig. 7. Measured and computed cross-shore variations of mean and standard deviation of free surface elevation and horizontal velocity for Test LD

and $S=0$ for these tests. The toe of the dune was located at $z=-0.33 \mathrm{~m}$ and there was no berm. The beach slope was decreased from $1 / 10$ to $1 / 90$ until $z=-2.7 \mathrm{~m}$ and increased to $1 / 25$ because of the finite flume length. The still water depth at the wave generator was $4.5 \mathrm{~m}$. The irregular waves measured in the still water depth of $3.5 \mathrm{~m}$ are specified as input to the numerical model. This seaward boundary location is chosen as $x=0$ and the toe of the dune is at $x=165.8 \mathrm{~m}$. Three tests (T01, T02, and T03) were conducted for the spectral peak periods $T_{p}=4.9,6.1$, and $7.3 \mathrm{~s}$, respectively. The significant wave height $H_{m 0}$ was 1.41 , 1.49 , and $1.52 \mathrm{~m}$ for Tests $\mathrm{T} 01, \mathrm{~T} 02$, and $\mathrm{T} 03$, respectively. The beach and dune profile was measured at time $t=0.0,0.1,0.3$, $1.0,2.04$, and $6.0 \mathrm{~h}$. The empirical parameters of the numerical model are kept the same as in the above comparison with the small-scale experiments. The constant nodal spacing is increased to $\Delta x=5 \mathrm{~cm}$, which is sufficient to resolve the steep dune slope.

Fig. 8 compares the measured and computed profiles at the end $(t=6 \mathrm{~h})$ of dune erosion Tests T01, T02, and T03. Only the zone of noticeable profile changes is shown in Fig. 8 for clarity. The numerical model underpredicts the dune erosion and corresponding depositional area in contrast to the comparison with the small-scale Experiments $\mathrm{H}$ and L shown in Figs. 4 and 5 perhaps because of the very different dune height and width. Table 2 lists the measured and computed values of the eroded area $A_{e}$ at $t=0.1,0.3,1.0,2.04$, and $6.0 \mathrm{~h}$ where van Gent et al. (2006) defined $A_{e}$ as the area eroded above the datum $z=0$. This definition is adopted here because the dune erosion was essentially limited to the area above $z=0$ in Fig. 8. The numerical model overpredicts $A_{e}$ initially and underpredicts $A_{e}$ subsequently. Nevertheless, $A_{e}$ is predicted within an error of $40 \%$. The numerical model predicts the increase of $A_{e}$ with the increase of the wave period $T_{p}$ but the degree of the increase is overestimated somewhat.

The computed hydrodynamic and sediment transport variables 


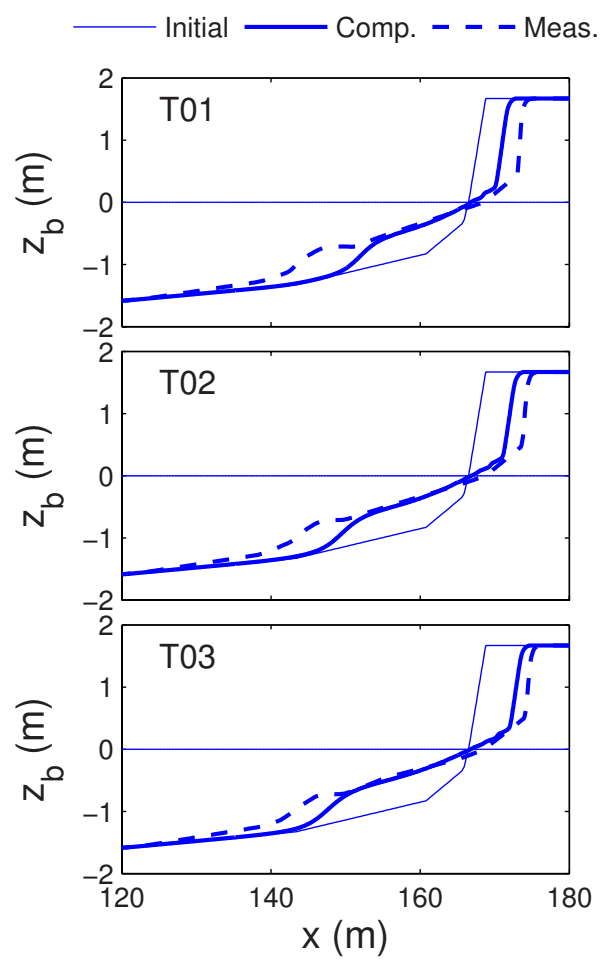

Fig. 8. Measured and computed profiles at end of dune erosion Tests T01 (top), T02 (middle), and T03 (bottom)

for the three tests are compared to find possible causes for the increased erosion with the increase of the wave period. Fig. 9 shows the computed cross-shore variations of $\bar{\eta}, \sigma_{\eta}, \bar{U}$, and $\sigma_{U}$ above the initial profile $z_{b}$ at $t=0$ which was the same for the three tests. The input value of $\sigma_{\eta}=H_{m 0} / 4$ at $x=0$ is slightly different for the three tests with $T_{p}=4.9,6.1$, and $7.3 \mathrm{~s}$. It is noted that the numerical model predicts the measured $\sigma_{\eta}$ as accurately as in Fig. 7 (Buck et al. 2007). The computed wave setup $\bar{\eta}$ on the steep dune slope increases with the increase of $T_{p}$ where the present numerical model does not include the upper swash zone which is not always wet. The wave action represented by $\sigma_{\eta}$ and $\sigma_{U}$ and the offshore (negative) current $\bar{U}$ increase slightly with the increase of $T_{p}$, resulting in the slight increase of the dune erosion.

\section{Effect of Incident Wave Angle}

The numerical model calibrated for the small-scale and largescale experiments under the normally incident waves is used to

Table 2. Temporal Increase of Measured and Computed Dune Erosion Area $\left(\mathrm{m}^{2}\right)$ for Three Large-Scale Tests

\begin{tabular}{|c|c|c|c|c|c|c|}
\hline \multirow{2}{*}{$\begin{array}{l}\text { Time } \\
\text { (h) }\end{array}$} & \multicolumn{2}{|c|}{$\begin{array}{c}\text { Test T01 } \\
\left(T_{p}=4.9 \mathrm{~s}\right)\end{array}$} & \multicolumn{2}{|c|}{$\begin{array}{c}\text { Test T02 } \\
\left(T_{p}=6.1 \mathrm{~s}\right)\end{array}$} & \multicolumn{2}{|c|}{$\begin{array}{c}\text { Test T03 } \\
\left(T_{p}=7.3 \mathrm{~s}\right)\end{array}$} \\
\hline & Meas. & Comp. & Meas. & Comp. & Meas. & Comp. \\
\hline 0.10 & 0.90 & 1.07 & 1.01 & 1.30 & 1.15 & 1.48 \\
\hline 0.30 & 2.13 & 1.97 & 2.29 & 2.40 & 2.48 & 2.73 \\
\hline 1.00 & 4.23 & 3.49 & 4.58 & 4.30 & 5.31 & 4.94 \\
\hline 2.04 & 5.88 & 4.54 & 6.32 & 5.66 & 7.10 & 6.60 \\
\hline 6.00 & 8.60 & 5.66 & 9.57 & 7.05 & 9.85 & 8.27 \\
\hline
\end{tabular}
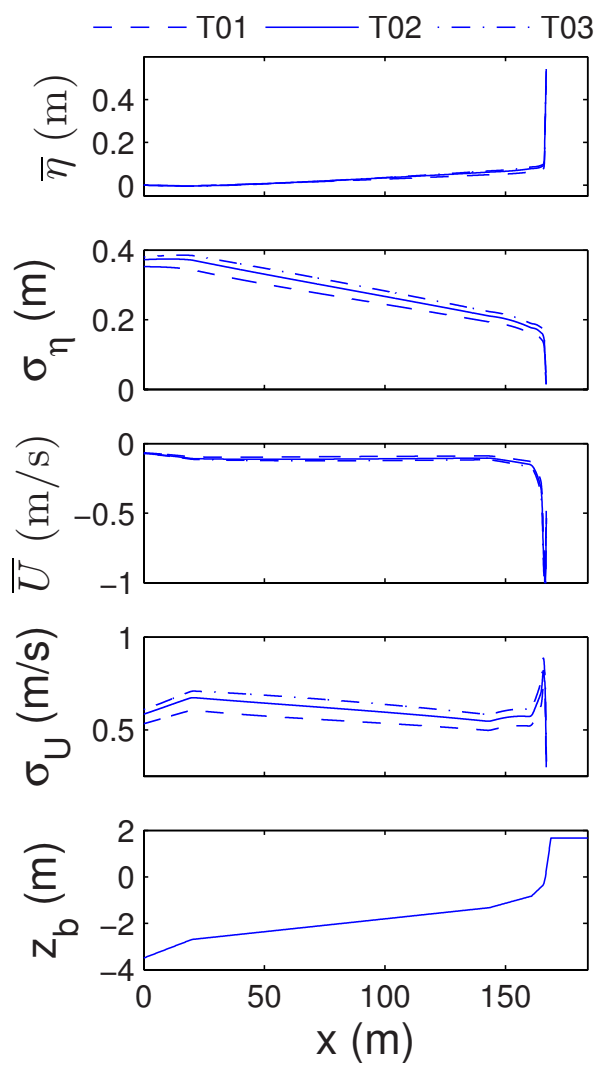

Fig. 9. Computed cross-shore variations of $\bar{\eta}, \sigma_{\eta}, \bar{U}$, and $\sigma_{U}$ above initial profile $z_{b}$ for Tests T01, T02, and T03

examine the effect of the incident wave angle on the berm and dune erosion. The incident wave angle for these experiments is varied as if these experiments had been conducted in wave basins. In reality, it may be difficult to maintain the alongshore uniformity of berm and dune erosion in a wave basin (Payo et al. 2006). Nevertheless, it is worthwhile to examine the effect of the incident wave angle on the berm and dune erosion which may not be the maximum under the normally incident waves. As the incident wave angle increases, the onshore wave energy flux decreases but obliquely incident waves generate the longshore current which increases the sediment mobility and suspension. Consequently, the berm and dune erosion may not decrease monotonically with the increase of the incident wave angle.

The computations made for Experiments $\mathrm{H}$ and $\mathrm{L}$ are repeated for the incident wave angle $\theta=15,30$, and $45^{\circ}$ at $x=0$. The computed eroded area $A_{c}$ for the given time $t$ and angle $\theta$ is divided by the computed eroded area $A_{e}$ for $\theta=0^{\circ}$, denoted as $A_{0}$, at the same time $t$ where the computed $A_{0}$ is plotted as a function of $t$ in Fig. 6. Fig. 10 shows the computed ratio $A_{e} / A_{0}$ at $t=1.00$, 2.00, 3.00, 3.67, 4.89, and $6.11 \mathrm{~h}$ for Experiments $\mathrm{H}$ and $\mathrm{L}$ with $\theta=15,30$, and $45^{\circ}$. The computed $A_{e}$ is larger than $A_{0}$ for $\theta=15$ and $30^{\circ}$ and smaller than $A_{0}$ for $\theta=45^{\circ}$ for $t=1.00-6.11 \mathrm{~h}$. The ratio $A_{e} / A_{0}$ deviates more from unity for $\theta=15$ and $45^{\circ}$ as well as for Experiment $\mathrm{H}$. The effect of the incident wave angle depends on the initial berm geometry which affects the irregular breaking wave transformation and wave-induced longshore current. The ratio $A_{e} / A_{0}$ tends to approach unity as the berm is eroded and its influence diminishes. In short, the effect of the incident wave angle on the berm and dune erosion is on the order of $20 \%$.

The same computation is made for the large-scale dune erosion Tests T01, T02, and T03. Fig. 11 shows the computed ratio 


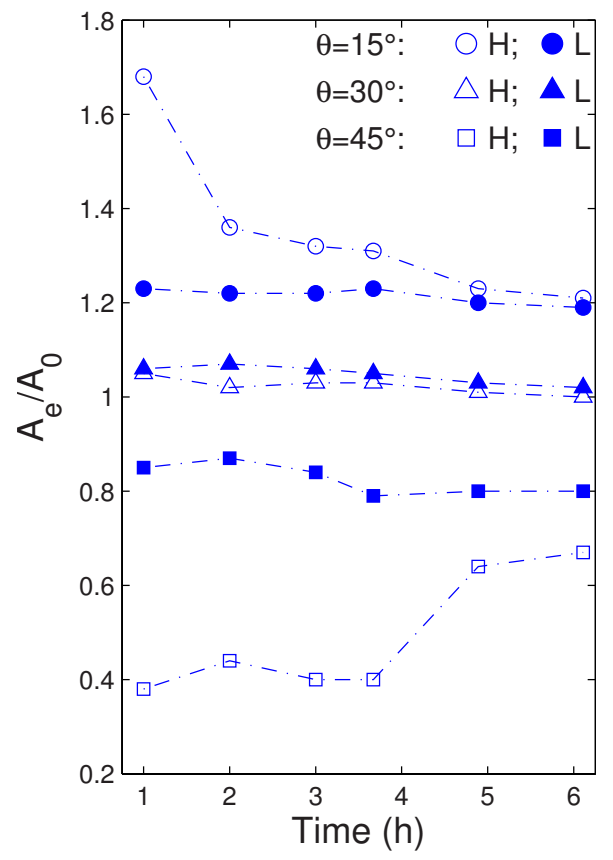

Fig. 10. Temporal variation of computed ratio $A_{e} / A_{0}$ for Experiments $\mathrm{H}$ and $\mathrm{L}$ with incident wave angle $\theta=15,30$, and $45^{\circ}$

$A_{e} / A_{0}$ at time $t=0.1,0.3,1.0,2.04$, and $6.0 \mathrm{~h}$ for $\theta=15,30$, and $45^{\circ}$. The computed values of $A_{e} / A_{0}$ for the given $t$ and $\theta$ are almost the same for the three tests, indicating that the effects of the incident wave angle and wave period are almost independent for these tests. The ratio $A_{e} / A_{0}$ is less than unity and decreases with the increase of $\theta$ for the steep and high dune with no berm. The ratio tends to approach constant as the beach slope in front of the dune becomes gentler as shown in Fig. 8 .

The computed hydrodynamic and sediment transport variables for the different incident wave angles are compared to explain the computed ratios shown in Figs. 10 and 11. The compared results are presented by Buck et al. (2007). As an example, Fig. 12 shows the computed cross-shore variations for Test $\operatorname{LD}$ with $\theta=0$

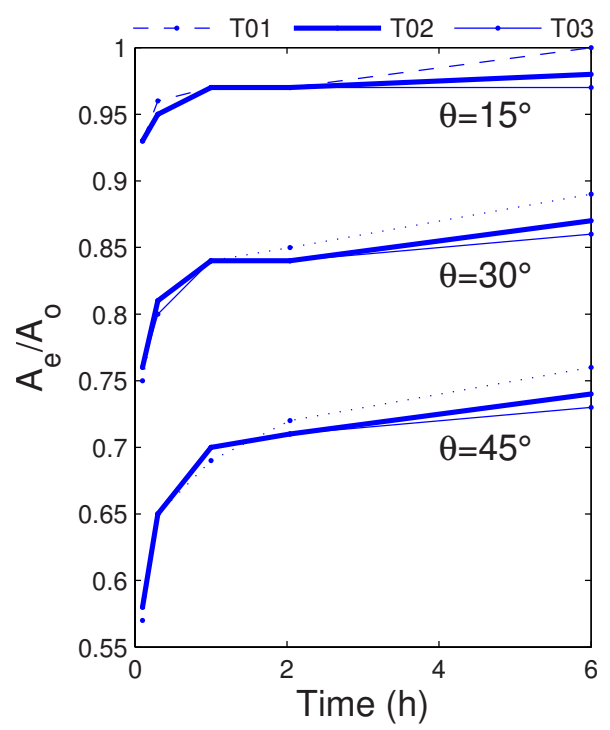

Fig. 11. Temporal variation of $A_{e} / A_{0}$ for dune erosion Tests T01, T02, and T03 with $\theta=15,30$, and $45^{\circ}$
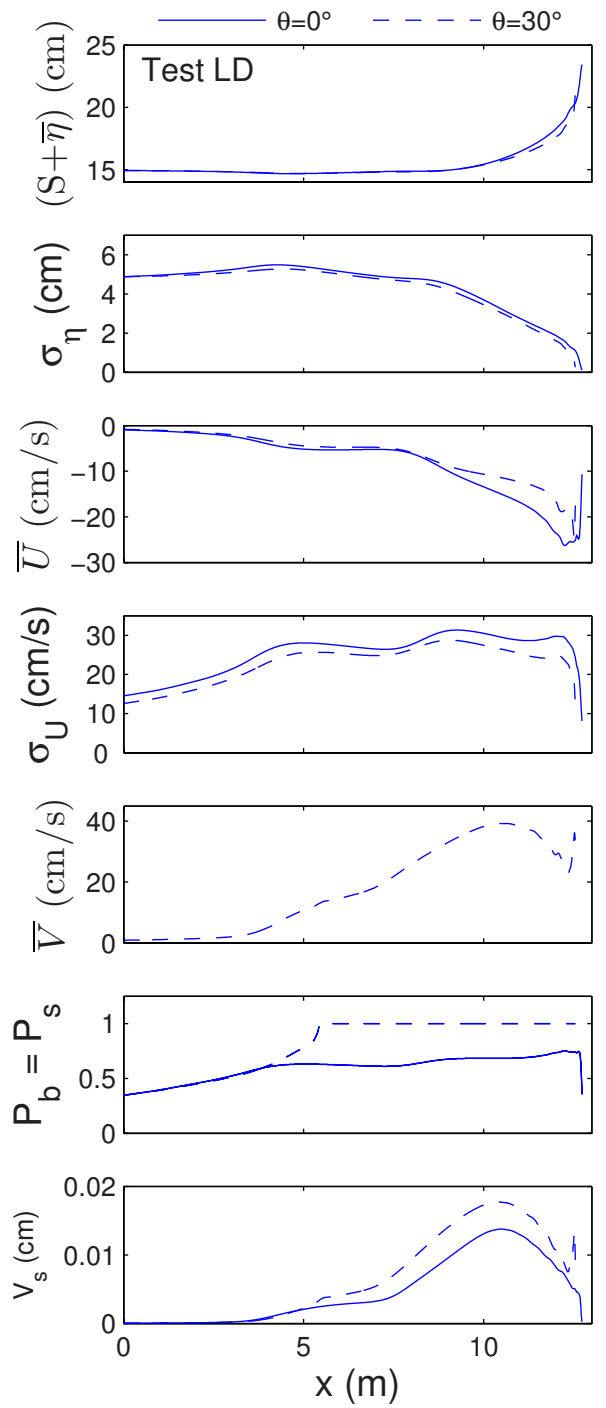

Fig. 12. Computed cross-shore variations of $(S+\bar{\eta}), \sigma_{\eta}, \bar{U}, \sigma_{U}, \bar{V}$, $P_{b}=P_{s}$, and $V_{s}$ for Test LD with $\theta=0$ and $30^{\circ}$

and $30^{\circ}$ where Fig. 7 corresponds to $\theta=0^{\circ}$. The mean water level $(S+\bar{\eta})$, the wave action represented by $\sigma_{\eta}$ and $\sigma_{U}$, and the offshore current $\bar{U}$ decrease with the increase of the incident wave angle $\theta$. However, the longshore current $\bar{V}$ for $\theta=30^{\circ}$ is large on the eroded berm, whereas $\bar{V}=0$ for $\theta=0^{\circ}$. The probability $P_{b}$ of sediment movement and the probability $P_{s}$ of sand suspension turn out to be the same for the fine sand used in Experiments $\mathrm{H}$ and L. These probabilities given by Eqs. (4) and (5) include the effect of the longshore current and are larger for $\theta=30^{\circ}$. The suspended sediment volume $V_{s}$ per unit horizontal bottom area given by Eq. (13) also includes the effect of the longshore current through $P_{s}$ and the energy dissipation rate $D_{f}$ due to bottom friction. The computed $V_{s}$ is larger for $\theta=30^{\circ}$.

The sediment transport rates computed using Eqs. (7), (9), and (10) for Test LD with $\theta=0$ and $30^{\circ}$ are shown in Fig. 13. The cross-shore bed load transport rate $q_{b x}$ is positive (onshore) and its cross-shore variation is different for $\theta=0$ and $30^{\circ}$ where the spike of $q_{b x}$ for $\theta=30^{\circ}$ near the landward limit is related to the spike of $\bar{V}$ in Fig. 12. The cross-shore suspended sediment transport rate $q_{s x}$ is negative (offshore) and its cross-shore variation is similar for $\theta=0$ and $30^{\circ}$. The computed $q_{b x}$ and $q_{s x}$ are on the order of 

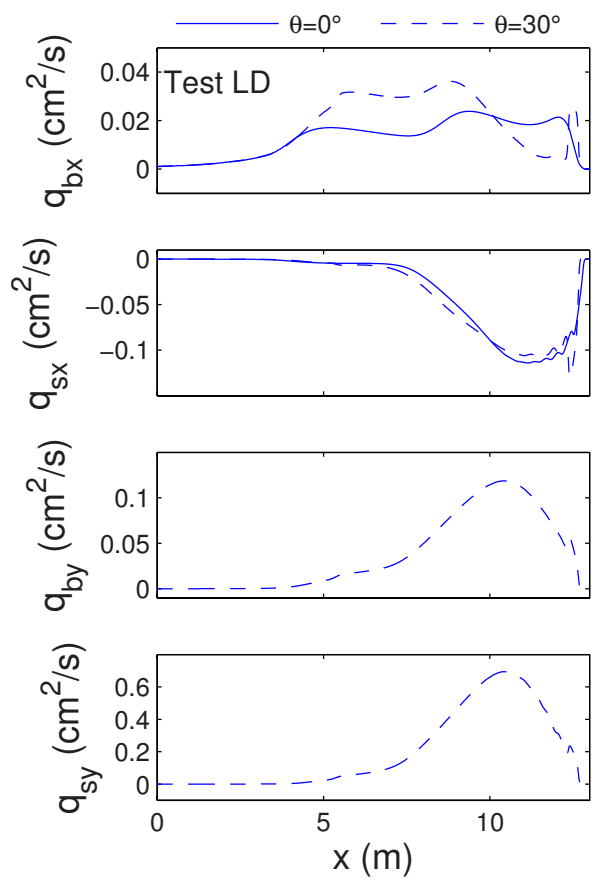

Fig. 13. Computed cross-shore and longshore bed load and suspended sediment transport rates for Test LD with $\theta=0$ and $30^{\circ}$

0.02 and $-0.1 \mathrm{~cm}^{2} / \mathrm{s}$, respectively. The net cross-shore sediment transport rate $q_{x}=\left(q_{b x}+q_{s x}\right)$ is dominated by $q_{s x}$ and similar for $\theta=0$ and $30^{\circ}$. This explains $A_{e} / A_{0}=1.05$ for Test LD and $\theta=30^{\circ}$ in Fig. 10. On the other hand, the longshore bed load transport rate $q_{b y}$ and the longshore suspended sediment transport rate $q_{s y}$ are zero for $\theta=0^{\circ}$. For $\theta=30^{\circ}, q_{b y}$ and $q_{s y}$ are on the order of 0.1 and $0.5 \mathrm{~cm}^{2} / \mathrm{s}$, respectively. The combined longshore sediment transport rate $q_{y}=\left(q_{b y}+q_{s y}\right)$ is much larger than the cross-shore transport rate $q_{x}$. The total longshore sediment transport rate $Q_{y}$ is estimated by integrating the computed $q_{y}$ with respect to $x$. The estimated $Q_{y}$ increases with the increase of $\theta=15,30$, and $45^{\circ}$ as expected from the CERC formula (Coastal Engineering Manual 2003) and decreases with time as the berm slope becomes gentler. The decrease of $Q_{y}$ from $t=0$ to $6.11 \mathrm{~h}$ is approximately 10 and $20 \%$ for Experiments $\mathrm{H}$ and $\mathrm{L}$, respectively. This indicates that the berm geometry affects both cross-shore and longshore sediment transport.

The compared results for the dune erosion Tests T01, T02, and T03 are fairly similar to those shown in Figs. 12 and 13 except that the computed dimensional variables are larger for these largescale tests. The probabilities of sediment movement and suspension are larger and almost unity. For these tests, the offshore suspended sediment transport rate $q_{s x}$ on the beach in front of the eroding dune is computed to be larger for $\theta=0^{\circ}$, which explains $\left(A_{e} / A_{0}\right)<1$ in Fig. 11. The estimated longshore sediment transport rate $Q_{y}$ for the given $\theta=15,30$, and $45^{\circ}$ decreases from $t=0$ to $t=6 \mathrm{~h}$ by approximately $30 \%$. It should be stated that the computed results for the obliquely incident waves could not be validated for lack of available data.

\section{Conclusions}

Two small-scale experiments were conducted to examine the effect of the berm geometry on the temporal variation of berm and dune erosion during a storm. The still water level was increased to the level of initiation of dune breaching and then decreased to the initial level. The berm geometry influenced the temporal variation of the berm erosion but its effect became small after the berm was eroded completely. Simple formulas for the cross-shore and longshore transport rates of suspended sediment and bed load on beaches are proposed by synthesizing available data and formulas. The combined wave and current model by Kobayashi et al. (2007) is used to provide the hydrodynamic input required for the sediment transport model. The proposed numerical model predicts the measured berm and dune erosion within errors of a factor of two but cannot predict the deposited area accurately as shown in Figs. 4, 5, and 8. The numerical model is also shown to predict the dune erosion measured in the three large-scale tests by van Gent et al. (2006) within a factor of two. The numerical model is used to investigate the influence of the wave period on the dune erosion in these three tests as well as to examine the effect of the incident wave angle which is computed to be on the order of $20 \%$. The berm geometry is found to affect both cross-shore and longshore sediment transport. The total longshore sediment transport rate decreases as the berm slope becomes gentler.

The numerical model will need to be validated using additional data. The present comparisons are limited to the fine uniform sands with median diameters $d_{50}=0.18$ and $0.20 \mathrm{~mm}$. Largescale data on berm and dune erosion under obliquely incident waves are essential for verification of the proposed formulas for bed load and suspended load. The numerical model will also need to be validated using field data.

\section{Acknowledgments}

This study was supported by the U.S. Army Corps of Engineers under Contract No. W912BU-07-C-0013. The third writer was supported by the Spanish Postdoctoral Scholarship MEC/ FULBRIGHT. The writers would like to thank Marcel van Gent for providing dune erosion data used in this study.

\section{References}

Bagnold, R. A. (1966). "An approach to the sediment transport problem from general physics." U.S. Geol. Surv. Prof. Pap., 422-I.

Bailard, J. A. (1981). "An energetics total load sediment transport model for a plane sloping beach." J. Geophys. Res., 86(C11), 10,93810,954 .

Buck, M., Kobayashi, N., Payo, A., and Johnson, B. D. (2007). "Experiments and numerical model for berm and dune erosion." Research Rep. No. CACR-07-03, Center for Applied Coastal Research, Univ. of Delaware, Newark, Del.

Coastal engineering manual, Part V. (2003). U.S. Army Engineer Research and Development Center, Vicksburg, Miss.

Dohmen-Janssen, C. M., and Hanes, D. H. (2002). "Sheet flow dynamics under monochromatic nonbreaking waves." J. Geophys. Res., 107(C10), 3149.

Donnelly, C., Kraus, N., and Larson, M. (2006). "State of knowledge on measurement and modeling of coastal overwash." J. Coastal Res., 22(4), 965-991.

Kobayashi, N. (1987). "Analytical solution for dune erosion by storms." J. Waterway, Port, Coastal, Ocean Eng., 113(4), 401-418.

Kobayashi, N., Agarwal, A., and Johnson, D. B. (2007). "Longshore current and sediment transport on beaches." J. Waterway, Port, Coastal, Ocean Eng., 133(4), 296-306.

Kobayashi, N., and Johnson, B. D. (2001). "Sand suspension, storage, advection, and settling in surf and swash zones." J. Geophys. Res., 106(C5), 9363-9376. 
Kobayashi, N., Payo, A., and Johnson, B. D. (2008a). "Suspended sand and bedload transport on beaches." Handbook of coastal and ocean engineering, World Scientific, Singapore, 1-20.

Kobayashi, N., Payo, A., and Schmied, L. D. (2008b). "Cross-shore suspended sand and bedload transport on beaches." J. Geophys. Res., 113, 2007JC004203.

Kobayashi, N., Tega, Y., and Hancock, M. W. (1996). "Wave reflection and overwash of dunes." J. Waterway, Port, Coastal, Ocean Eng., 122(3), 150-153.

Kobayashi, N., Zhao, H., and Tega, Y. (2005). "Suspended sand transport in surf zones." J. Geophys. Res., 110, C12009, 2004JC002853.

Kriebel, D. L., and Dean, R. G. (1985). "Numerical simulation of timedependent beach and dune erosion." Coastal Eng., 9, 221-245.

Larson, M., and Kraus, N. (1989). "SBEACH: Numerical model for simulating storm-induced beach change. Report 1-Empirical foundation and model development." Technical Rep. No. CACR-89-9, U.S. Army Engineer Research and Development Center, Vicksburg, Miss.

Madsen, O. S., and Grant, W. D. (1977). "Quantitative description of sediment transport by waves." Proc., Coastal Engineering 1976, Proc., 15th Coastal Engineering Conf., ASCE, Reston, Va., 10931112.
Nairn, R. B., and Southgate, H. N. (1993). "Deterministic profile modelling of nearshore processes. Part 2: Sediment transport and beach profile development." Coastal Eng., 19, 57-96.

Payo, A., Kobayashi, N., and Kim, K. (2006). "Beach renourishment strategies." Coastal Engineering 2006, Proc., 30th Coastal Engineering Conf., World Scientific, Singapore, 4129-4140.

Ribberink, J. S. (1998). "Bed-load transport for steady flows and unsteady oscillatory flows." Coastal Eng., 34, 59-82.

Ribberink, J. S., and Al-Salem, A. A. (1994). "Sediment transport in oscillatory boundary layers in cases of rippled beds and sheet flow." J. Geophys. Res., 99(C6), 12,707-12,727.

Schmied, L., Kobayashi, N., Puleo, J., and Payo, A. (2006). "Cross-shore suspended sand transport on beaches." Coastal Engineering 2006, Proc., 30th Coastal Engineering Conf., World Scientific, Singapore, 2511-2523.

van Gent, M. R. A., Coeveld, E. M., Walstra, D. J. R., van de Graaff, J., Steetzel, H. J., and Boers, M. (2006). "Dune erosion tests to study the influence of wave periods." Coastal Engineering 2006, Proc., 30th Coastal Engineering Conf., World Scientific, Singapore, 2779-2791. 